\title{
An analysis of the disagreement about added value by regional climate models
}

\author{
Elisabeth A. Lloyd ${ }^{1}$ (D) Melissa Bukovsky² $\cdot$ Linda O. Mearns ${ }^{2}$
}

Received: 5 March 2018 / Accepted: 30 July 2020 / Published online: 17 August 2020

(c) The Author(s) 2020

\begin{abstract}
In this paper we consider some questions surrounding whether or not regional climate models "add value," a controversial issue in climate science today. We highlight some objections frequently made about regional climate models both within and outside the community of modelers, including several claims that regional climate models do not "add value." We show that there are a number of issues involved in the latter claims, the primary ones centering on the fact that different research questions are being pursued by the modelers making the complaints against regional climate models. Further issues focus on historical deficiencies of particular-but not generalizable-failures of individual regional models. We provide tools to sort out these different research questions and particular failures, and to improve communication and understanding surrounding added value in climate modeling and philosophy of climate science.
\end{abstract}

Keywords Regional climate models $\cdot$ Added value $\cdot$ Climate models $\cdot$ High resolution · Precipitation modeling · Logic of research questions · Complementarity · Global climate models

\section{Introduction}

In this paper we consider the questions surrounding whether or not regional climate models "add value" to long-term climate change projections, a controversial issue in

\footnotetext{
Elisabeth A. Lloyd

ealloyd@indiana.edu

Melissa Bukovsky

Bukovsky@ucar.edu

Linda O. Mearns

Lindam@ucar.edu

1 Department of History and Philosophy of Science and Medicine, Indiana University, Ballantine Hall 652, Bloomington, IN 47401, USA

2 National Center for Atmospheric Research, PO Box 3000, Boulder, CO 80307-3000, USA
} 
climate science today. We highlight some objections frequently made about regional climate models both within and outside the community of modelers, including several claims that regional climate models do not "add value." We show that there are a number of issues involved in the latter claims, the primary ones centering on the fact that different research questions are being pursued by the modelers making the complaints against regional climate models. General views about regional climate models can influence both funding and research allocation decisions as well as the standing of a type of research in science, as we know. In this paper, we provide tools to sort out these different research questions and particular failures, and to improve communication and understanding surrounding added value in climate modeling and philosophy of climate science. Our philosophical analysis will not deal with the detailed evidence supporting specific regional climate models, but rather, will focus on examining the research questions concerning those models and their responsive answers, and the general types or categories of evidence in their support. For those interested in the former, an abundance of detailed empirical and observational evidence supporting the accuracy of regional models exists and can be found by following the literature cited herein. In Sect. 2 we introduce regional climate models and their values, illustrating the ideas with several examples, while in Sect. 3 we review three typical sets of challenges that regional models do not add value. In Sect. 4 we use our philosophical approach to research questions to propose insight into some of the failures of communication and understanding that go into such challenges, while in Sect. 5 we examine a couple of definitions of added value, analyzing their components and differences. Here we discuss the issue of complementarity of regional climate models with global models, introducing the wrinkle of competition between regional and global models in description of some components, such as precipitation, and put these features into the context of the equivocal IPCC definitions of added value. We also examine the essential role of understanding causes in the regional climate models. Section 6 sums up the results of the paper.

\section{Regional climate models and their values and limitations}

The first thing we need to do is examine what regional climate models are like, before we can address any objections to them, as most philosophers of science have only passing familiarity with such models. Unlike the global climate models, they do not represent the entire earth, but only a single region of varied size, such as the North American, southwestern USA, or the Great Lakes region, or Europe. Such regional climate models or RCMs usually are run at finer spatial resolutions than global models.

Whereas most global climate models are run at resolutions of 100 to $200 \mathrm{~km}$, regional models typically are run at spatial resolutions between $2,12,25$, or $50 \mathrm{~km}$, and are thus capable of representing much finer climate and weather causal processes. For example, RCMs can better represent orographic precipitation (precipitation associated with complex terrain) because they better resolve the topography of a region compared to global models. More generally, they are also especially useful in modeling highly variable terrain, such as coastlines and mountainous regions (Ciarlo et al. 2020; IPCC 2013, Ch. 14). 
An essential aspect of simulating regions with RCMs are the use of boundary conditions from coarser models that drive the RCM at its boundaries. Typically, in standard use of RCMs in climate change research, the RCMs are first driven by reanalyses (close to using observed boundary conditions) for a series of years (e.g., several decades). This simulation is considered the 'best' possible simulation for the particular RCM from the point of view of minimizing biases (differences from actual observed datasets). Then the model is run with boundary conditions from global climate models, which have their own biases, and the RCM simulation will be affected by these biases from the boundary conditions. As summarized in Giorgi (2019), "The presence of the constraint by the boundary forcing has important consequences for the use of RCMs, in that large errors in the forcing fields make the RCM simulations highly questionable, if not essentially useless, for application purposes." The issue of the quality of boundary conditions from the GCMs will emerge at several points in our discussion.

Regional modelers went through some years of trouble with accuracy and uncertainty of modeling regional systems, but they have made much headway in the past several decades or so in understanding and reducing uncertainty in structural and parametric aspects of modeling (e.g., see Arritt and Rummukainen 2011; Rummukainen et al. 2015; Olesen et al. 2018; Giorgi 2019). RCMs are especially useful in modeling precipitation and extremes of precipitation (Mearns et al. 2012; Bukovsky et al. 2017; Kendon et al. 2017).

Consider the case of complex topographical relief and the distribution of snow in the Rocky Mountains and the High Sierra in the Western US. The available global climate models have very little detail on snow distribution and elevations of the mountains, and thus also very few or inaccurate details concerning the distribution of albedo, and temperature feedback from albedo, which concerns the reflection of radiation from light colored surfaces such as snow (Leung and Qian 2003; Rasmussen et al. 2011).

Without accurate regional climate models to downscale these feedbacks or causes, and to put the snow, mountain passes, and valleys in the right places, and at the right times, we will get snow in all the wrong places, and thus will get snow albedo feedbacks, and temperature feedbacks, in all the wrong places, and thus the temperatures will be incorrect in many parts of the model domain. Hence, the fine-grained, processoriented picture that we get using empirically and observationally accurate regional climate models will be better at producing the real temperature feedbacks, as they have been (Leung and Qian 2003; Qian et al. 2010; Walton et al. 2016, Sun et al. 2016).

This is a good example of how not understanding the basic fine-grained processes can foul up our predictions concerning basic, and originally large-scaled, climate variables such as temperature. The IPCC (the authoritative Intergovernmental Panel on Climate Change under the auspices of the UN and the World Meteorological Organization) called attention to the large size of the bias-reductions (i.e., error reductions, or corrections) given by the regional climate models of snow: "Bias reductions are large for snowpack in topographically complex Western North America, as revealed by 2- to 20-km resolution regional simulations" (2013, p. 1258; Qian et al. 2010).

Confidence in basic variables such as temperature and albedo lays at the heart of the utility of RCMs both for research and for pragmatic applications in, for example, adaptation planning in communities, that is, community preparation for warming trends 
and extreme weather events. Here, we can see the social as well as representational and epistemic values associated with RCMs playing key roles.

The snow example illustrates the success of RCMs in topographically complex regions. But regional climate models can also be very effective even when there is no complex topography, as is shown in recent modeling of the US Southern Great Plains (Bukovsky et al. 2017). The improvements in understanding the mechanisms that drive climate offered by regional models over global models of the same regions are clear from these very recent applications and analyses. Under conditions of increased greenhouse gases, both large-scale dynamical processes and local land-atmosphere feedbacks drive an early end to the spring wet period, as the precipitation shifts north earlier in the season, which then intensifies late summer drying. These processes and the precipitation are well-modeled by the regional climate models of the North American Regional Climate Change Assessment Program (NARCCAP). The 'credibility' of these regional model projections was assessed based on model accuracy in simulating twentieth century climate, and on physical and mechanistic plausibility of the projections in a warming climate (Bukovsky et al. 2017). This latter requirement was added to the usual standard of historical adequacy, following Christensen et al. (2013, p. 1255), as historical accuracy is necessary but not wholly sufficient for determining credibility. The modelers were also "examining the mechanisms behind the precipitation changes, assessing whether or not they are well-simulated, and whether or not they are changing in a manner that makes sense in a warming climate" (Bukovsky et al. 2017, p. 1). Additionally, it was noted in Bukovsky et al. (2017) where specific causal processes had been observed to be changing in a manner consistent with the projections, lending a greater degree of confidence in the projections for these specific processes.

In this study of the mean precipitation of the Southern Plains, Bukovsky et al. found the baseline simulation and projections of mean precipitation to be more credible from the regional climate models than from the GCMs that provided their driving conditions (2017, p. 28). The pattern of precipitation in the Southern Plains in the RCMs was superior to that of the GCMs to start, as the GCMs could not capture the west-toeast gradient in precipitation, and as shown this was likely due to the precipitation processes being better represented in the RCMs (2017, p. 9). This is an example of significant "added value" of the regional models. This case aids in our analysis of the interrelationships between the two levels of models. The projections of precipitation from the regional models were greater in magnitude than those from the global model ensembles, from the CMIP3 and CMIP5 suites, a topic they note is worth further study. Their confidence in the regional model results was based on the "consensus and credibility" they found across the majority of the regional models they studied (Bukovsky et al. 2017, p. 30). In sum, regional models can provide added value even when there is no topographic difference driving the differences between global and regional models.

In general, it is often enlightening and important to consider the relationships between the driving GCM and any given RCM. A GCM may be wrong or empirically inadequate in a variety of ways, but the RCM has to start with those values or base state, as its boundary conditions (see Arritt and Rummukainen (2011); Rummukainen et al. 2015, Olesen et al. 2018; and citations in FN \#1). So the RCM may 
also be wrong at that scale, because of inadequate boundary conditions, but then the RCM might still be able to add value in finer scale details. These finer scale details may be closer to an accurate account of the climate, overall, despite the insufficient boundary conditions coming from the GCM, as we saw in the Southern Great Plains study. Thus, an RCM may be empirically weak because of the empirically weak GCM boundary conditions, and may provide "Useless Added Value" because of them. "Useless Added Value", a term coined by Melissa Bukovsky and used when presenting her work on the SW North American monsoon (2015b, 2016), captures the case in which the fine-scale model presents information and captures processes correctly at the higher resolution scale, but this added value becomes irrelevant when it is overshadowed by larger errors caused by errors in the boundary conditions. For example, a regional model may correctly simulate and add the near-surface flow of wind over the Gulf of California during monsoon season (a key monsoon season trait that cannot be simulated by models incapable of resolving the Gulf of California), but then the RCM may not simulate rain during the monsoon season due to larger-scale errors inherited from its GCM boundary conditions (Bukovsky et al. 2013, 2015a). Thus, the greater detail has no value. These are cases of incompatibility of the two levels of models that are significant, in our analysis. ${ }^{1}$ It should be noted that this was also the case in the southern Great Plains study, where one of the GCM simulations was judged to have such flawed boundary conditions that none of the RCM simulations driven by that GCM were considered credible (Bukovsky et al. 2017).

Now that we have considered several instances of what regional climate models can actually do, in the western US mountains and the Southern US Plains, let us consider the question of "added value". As regional climate modeler Alejandro Di Luca and colleagues noted, added value "remains an important open question for the community" (Di Luca et al. 2012, p. 1229). But what is it? What are the arguments about? In this paper, we aim to decode and untangle some of the heated controversies surrounding added value. Upon the introduction of one of the authors to the climate community, she was surprised to hear the repeated challenges from some members of the global modeling community and other climate scientists regarding regional models: what could regional models really add? Were they worth the investment? Weren't they a waste of money? Why not wait until the global models achieve a finer resolution? Weren't the regional models always too empirically weak or faulty to do a valuable or useful job? Indeed, do they have any "added value"?

In the interest of clarity, we reformulated these questions as: "How do regional climate models exhibit epistemic, representational, and pragmatic values? How do these compare with global models? In what sense do regional climate models add value compared to global models?" And, "How can a philosopher help sort out these debates in climate science?"

\footnotetext{
1 See discussion of Big Brother experiments in Denis et al. (2002). Best Practices in regional modeling are also discussed in Arritt and Rummukainen (2011), and Rummukainen et al. (2015) as well as at the following sites: https://www.serdp-estcp.org/Program-Areas/Resource-Conservation-and-Resiliency/ Infrastructure-Resiliency/Use-of-Climate-Information-for-Decision-Making-and-Impacts-ResearchState-of-our-Understanding; https://na-cordex.org/guidance-data-use; Benestad et al. (2017); https://nacordex.org/guidance-data-use; and Mearns et al. (2003).
} 
Within our approach, typical epistemic values include consistency, precision, accuracy, empirical support, testability, scope, and clarity, while representational values place a positive valance on having reasonable or acceptable representations of certain aspects of the climate system. The representational values can depend on the interests of and relevance to the modeler or the user, and are not solely epistemic (see van Fraassen 2004, 2008; Giere 2004). Representational values involve more than just whether we know something, they address what we want to know, and sometimes why. These representations can involve mean temperature over large regions, for instance, the eastern US, in the case of the global models, or hourly precipitation, and storms, in the case of the regional models. The fact that representational values frequently differ between global and regional modelers is often ignored by those disparaging regional models, and we have an example of that, below. The fact that regional climate models often make it easier to visualize key features of climate, such as local precipitation, terrain, or land use and land cover, does not necessarily make them more accurate, but it does make them more accessible to users than the global models, a pragmatic virtue. They help make the model simulations look more like where you live, for instance, a situation that can be subject to "the seduction of (spatial) resolution." The fact that they are rigorously and independently confirmed through empirical and observational evidence therefore is extremely significant, thus confirming their epistemic value (See Footnote \#1; Giorgi et al. 2016; Giorgi 2019). Finally, pragmatic values such as explanatory power and simplicity, as well as care for the community, and community interests, round out our relevant values. ${ }^{2}$ In sum, the "added value" that is at stake in the debates about the value to the climate community and policy makers of regional climate models is frequently a hybrid of many types of values-social, epistemic, pragmatic, and representational; it is not merely epistemic, as is suggested or implied by some of the more formal definitions we shall consider in Sect. 5.

\section{Challenges that regional models do not 'add value'}

In one case in which the added value of regional climate models was challenged, global (rather than regional) modelers Pavan Racherla and his colleagues (2012) sought measures of regional model performance representing mean climate change over time. Using these measures, they asked the research question: did the regional model add value compared to the global model?

\footnotetext{
2 The idea is that when something is an answer to a particular question or interest of a person, it is interested, in a way, that involves more than whether it states a fact. It is not just a fact, but rather, a fact that is an answer to a question, or representing an interest of an inquirer. Epistemic values include things like consistency and logical relations, not relevance to a user. Famously, explanatory power is claimed to be a pragmatic rather than an epistemic virtue by empiricists like van Fraassen: it again is a virtue having to do with whether something answers a question or not, and does not have a logical relation of explanation, which has never successfully been shown to be a logical relation, of an epistemic sort. Thus, whether a fact answers a question and whether it serves a community are both pragmatic virtues of that fact. We can transfer this to claims about models: claims about models are things that are both explanatory and that can serve communities, both of which are pragmatic virtues. They do involve epistemic qualities, such as being good, well confirmed models, but they cannot be reduced to epistemic virtues.
} 
Racherla et al. concluded that the regional climate model simulations showed little added value to large regional temperature and precipitation climate change measures, in their experiment (2012), and this result was picked up and emphasized by Richard Kerr, in a widely read Opinion piece in Science (2013). He is a science writer perhaps not well versed in climate models captured by Racherla et al.'s critique, who wrote that while Racherla et al. found a "modest improvement over the [global] model, it's not so large." Kerr minimized this improvement, although many modelers take even slight improvements seriously. Kerr wrote that Racherla et al.'s modeling group "does not identify why [the regional model] fails to improve significantly on their global model" (2013, p. 173; emphasis added).

Kerr wrote, in a passage that was also read as indicating his hostility to RCMs, "it's far from a knockout punch to regional modeling" (2013, p. 174).

Kerr's and Racherla's articles aroused a heated debate in print about added value among climate scientists, with regional climate modeler Rene Laprise responding to Racherla et al.'s paper, and Drew Shindell, Racherla and colleagues, authors of the original paper, responding to Laprise. Laprise criticized Racherla et al.'s methods and noted that RCMs have often been shown to improve not large regional temperature and precipitation climate change measures, as Racherla et al. sought, but rather "the frequency distribution and representation of extremes for important climatic variables such as precipitation" (2014, p. 3880). That is, they are often most useful for telling us about extremes, such as floods, droughts, and related phenomena (see e.g., Kendon et al. 2014).

On the other side, in discussing additional research questions, Racherla's coauthors, Shindell et al. (2014) said that more research would be needed to determine the relationship between the skill of the competing global climate model or GCM and "the ability of [regional modeling] to improve the simulation (the GCM should not be too skillful at reproducing the quantity of interest or there will be little opportunity for added value...)" (2014, p. 3884; emphasis added). This was quite provocative, because RCMs simulated phenomena such as storms, floods, and drought, etc., that are often not modeled well or in detail by the GCMs because of their spatial resolution. Laprise wrote, about that comment, that it misunderstood what RCMs and added value are all about: "This statement is at variance with the stated goal of [regional climate modeling]: to add features that cannot be explicitly resolved by [low resolution] GCM," such as storms, detailed coastlines, peaked mountains, and narrow valleys (Laprise 2014, p. 3881). This is where the debate in print ended, in an unresolved state.

In a quintessential case of added value, Giorgi et al. (2016) considers that there are consistent indications from global climate model ensembles of reduced future summer precipitation over the European Alps, but notes that topography can modulate signals of precipitation change, and orographic convection can play a substantial role in changing expectations, which seems to be the effect in play in the Alps (2016). More specifically, an ensemble of regional simulations over the high Alps shows increases in precipitation despite broad-scale summer reduction in precipitation being projected by both global and regional model ensembles. This is apparently due to increased convective rainfall from higher potential instability by high-elevation surface heating and moistening (Giorgi et al. 2016). They note that these results challenge the coarse-scale projections 
of a ubiquitous decrease of summer precipitation over the Alps (Giorgi et al. 2016, p. 584).

This case of the unexpected increased precipitation in the high Alps thus demonstrates the added value of the high-resolution regional models versus the global models, which prove not to have the capability to model the relevant mechanisms needed at the appropriate scales. As Giorgi et al. put it: "Our findings...point to the added value provided by high-resolution models (here the RCMs) in a climate change context, specifically in the simulation of convection and associated topographic feedbacks, and can also provide valuable indications on the target resolution to use in future CORDEX activities" (2016, p. 588). Perhaps most impressive is the evidential robustness of these results in the Alpine context, being based not just on model projections, but on consistency across models using different convective schemes, across future time slices and with observed trends, along with the statistical significance of the signals, as well as robustness of the identification of an underlying process. The results are also robust across different observational variables (see Lloyd 2015b). As Giorgi et al. note, these "multiple elements of support add credibility" to the high-resolution effect they identify (2016, p. 588). It is exactly such credibility that is at stake when regional climate models are said to "add value".

The claim that regional modelers cannot deliver on their promises-an accusation often heard in the corridors in discussions among some global modelers and their fans-is put to the test in such contexts as in the Alps, when we would expect regional climate models to make a difference precisely because of the terrain. One climate science reader of our discussion of the Giorgi et al. (2016) work, ${ }^{3}$ above, claimed that "This is a clear example of the regional simulations giving cause for concern about the projections, but [the authors, anonymized] are very quick to leap to the conclusion that the RCM must be correct." While we understand that the conflict of Giorgi et al.'s model with the ensembles of global and regional models are what is causing the worry here, we find this negativity about RCMs to indicate exactly the sort of attitude we are concerned about, especially as the commentator seems not to recognize all the abundant variety of supporting evidence of seven types, altogether creating robust support for Giorgi et al.'s model of the High Alps (2016).

The same reader concluded with the following, after a discussion of the virtue of accuracy of models: "In my experience the camp looking for accuracy are very willing to allow that RCMs may have added value, they just want to see it actually demonstrated rather than asserted without evidence." This was very puzzling in the context of our discussion of the empirical, observational, and theoretical evidence for various RCMs documented in the literature. It is the sort of response that makes us feel unheard in the conversation, as we have reviewed and cited the robust variety of evidence supporting the RCMs, and don't know what else to do to highlight this evidence to make it more visible to our audience, to whom it seems perpetually invisible and inaccessible.

We see this problem of overgeneralizing the limitations or failures of regional climate models often. In a very early example, climate scientist, modeler, and analyst James Risbey has offered a series of critiques of both global and regional climate models. It is important to note that Risbey sees the value of RCMs in downscaling the

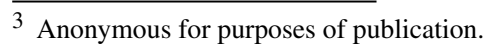


temperature field to bring out the effects of altitude and other effects on temperature. But Risbey emphasizes the weaknesses of precipitation in both GCMs and RCMs, seeing the RCM's representation of precipitation as more or less hopeless because of the unreliability of the boundary conditions from the GCMs. He believes that errors in the GCMs in the large and synoptic scale flow will be passed down to the RCMs, thus producing a precise but faulty projection, or what Bukovsky calls "useless added value" (Risbey and Stone 1996; Risbey et al. 2002). In an old paper that Risbey wrote with Peter Stone, they found that their own RCM of the Sacramento Basin was flawed due to issues with details of the atmosphere and the ocean circulation in the GCM (1996). More specifically, "[t]he stationary waves, jet streams and storm tracks in the North Pacific-North America region in the GCM simulations show major differences from observations, both in the mean and in their interannual variations" (Risbey and Stone 1996, p. 1441). Risbey and Stone continued: "Consequently, the larger-scale fields necessary for driving nested models and impact models for the basin, or for western North America in general, are problematic in these models" (1996, Risbey and Stone, 1441; see Risbey et al. 2002).

Risbey and Stone (1996) take regional climate modelers Giorgi and Mearns (1991) as a target; they note that regional modelers use ensembles of GCMs as a resource, "[y]et, this begs the question of whether any of the current GCMs are capable of adequately simulating the factors important for impact models and studies" (Risbey and Stone 1996, p. 1441; Risbey et al. 2002). They also write:

While the inherent limitations of the various empirical techniques have been emphasized [by the regional modelers] (Giorgi and Mearns 1991), it is also important to note that climate model advantages are potential advantages, which are mostly yet to be realized, as exemplified by the persistent model shortcomings discussed here (1996, p. 1466).

While this is a rather old critique, it resembles the recent critiques heard more informally quite strongly, and it provides a useful guide to the lines of argument and issues often pursued in informal settings today when discussing RCMs and their possible added value. But as Giorgi notes:

It is possible for example that, when running an RCM, biases averaged over subcontinental scale regions might be larger than for the driving GCM. Often this has been misinterpreted as a failure of the downscaling technique, while it is more simply a result of biases inherent in the particular model used over that domain. In other words, the results from one model experiment cannot be extended to the entire methodology (2019, p. 5709).

More importantly, GCMs have improved and continue to improve with time. In fact, regional modeler Gutowski (Gutowski et al. 2020) and global modeler Roberts (Roberts et al. 2018) agree, that "as resolutions of GCMs has increased, they have demonstrated potential for improving boundary conditions for RCM simulations (Roberts et al. 2018)" (quote from Gutowski et al. 2020). Hence, with a more accurate large-scale circulation with time, the added value in dynamical downscaling will be more useful rather than useless with time as well. 


\section{Understanding research questions and missed communications}

Our philosophical analytical approach to addressing the issue of added value in regional climate models emphasizes the structure of research questions and their ranges of appropriate and responsive answers. Choosing a research question usually implicitly or explicitly involves committing to certain representational, pragmatic, or other values, simultaneously, a topic that will not be our primary focus in this paper. But by clarifying the precise research question under scrutiny in a particular case, in detailed terms that the actual researchers do not necessarily usually utilize themselves, it often becomes clearer what the differences are between global and regional modelers' priorities, representational goals, and pragmatic aims (Lloyd 2015a). In addition to detailing the specific research question under consideration in a given case, we demonstrate in our Figures the various possible responsive answers to that research question, which differ significantly across distinct research questions. We find that once each debate is analyzed in terms of its precise research questions and responsive answers, many problems regarding representation become so clear, in a forehead-slapping kind of way, that it is surprising that there was ever a debate about them at all! Thus, it can appear, on our analysis, as if there ultimately was no real problem. This is an ideal outcome, we want to claim, because it lights the way towards a future agreement about distinct aims in global and regional climate modeling. Our goal, then, through analyzing the research questions and their possible responsive answers, is to dissolve a number of the disagreements among the parties of the debates about added value of regional modeling, so that all can proceed on their paths amicably, without dismissive critique or misunderstanding.

It is possible, in the discussions of the added value of RCMs, to make the error of thinking that everyone is arguing about the same thing: the same issue, the same ideas, research goals, and representational, epistemic, and pragmatic goals. They are not, as we emphasize in this section. One of the keys to the debates in climate science is that the climate community sometimes uses the term, added value, in conflicting ways. One of our aims is to cool down these conflicts by analyzing the various meanings of the term, "added value," within different research questions, while clarifying the mismatch of usage of the terms in the climate literature. We urge more clarity and precision of usage of the terms and definitions within climate science, in the context of the research questions being pursued.

One overall motivation for doing this work is that results from RCMs as well as statistical downscaling techniques are often used for impacts and adaptation work and provide policy-oriented climate information (Kothamarti et al. 2016; Kotharmarti et al. 2020). Thus, the relative added value of information generated from these various techniques turns out to be a significant issue concerning the funding and support of RCMs and these other downscaling techniques. However, research carefully comparing the added value of these different techniques has not been thorough enough (Kothamarti et al. 2016; Kothamarti et al. 2020). It should also be noted that global modelers are competing with regional modelers for funding, and some do not allow that RCMs add value, thus motivating less funding for regional modeling (see below).

Let us examine the problems by focusing on research questions and their answers. We ask, simply: What is the motivating research question? And then: What are appro- 
priate possible and responsive answers to that research question? Sometimes we can generate a list of such possible and responsive answers beforehand, based on theory (Lloyd 2015a). So it looks like this:

Figure 1: Research Question (RQ): What is being investigated?

Possible and Responsive Answers:

A: One possible and responsive Answer

A: Another possible and responsive Answer

A: A third possible and responsive Answer

A: And so on.....

The research question specifies 'What is being investigated?' with various possible and responsive answers under consideration. We have been looking at examples of some writers and modelers looking at RCMs with a critical eye in the previous Section. Recall that Laprise objected in print that Racherla et al. did not understand the purposes and goals of RCMs, when they showed that RCMs did not succeed in their aims; what was that argument really about? Did either side win that argument? What was at stake for the RCMs? Take Racherla et al.'s original research question as they originally posed it, represented in Figure 2. It looked as though Racherla et al., Laprise, and Shindell et al. were all arguing about the research question of whether RCMs add value compared to the GCM.

\section{Figure 2: Racherla et al. Research Question}

Racherla et al. Research Question (RQ): Did RCMs add value compared to the GCM?

Possible and Responsive Answers:

$\boldsymbol{A}$ : Yes, RCMs added value by improving our modeling of large-scale regional temperature and precipitation climate change measures

A: No, RCMs did not add value because they did not improve [very much] our modeling of large regional temperature and precipitation climate change measures

Racherla et al. found little help from the RCM, as represented in this analysis of the research questions, and their answer, "No", here, found little added value for regional models of the measures they sought. But compare Racherla's approach to the usual type of analysis using RCMs, represented in Figure 3 (Rummukainen 2016; NAS 2012).

\section{Figure 3: Usual RCM Research Question}

Usual RCM Research Question (RQ): Did RCMs add value compared to the GCM? Possible and Responsive Answers:

A: Yes, RCMs added value by improving our modeling of mean climate and extremes for a given historical period of time

$\boldsymbol{A}$ : No, RCMs did not add value: they did not improve our modeling of mean climate and extremes for a given historical period of time

Here, you see the usual answer that RCMs usually or often $d o$ add value, in the context of modeling mean climate and extremes for a given historical period of time.

Let's look at that contrast again, this time by contrasting the more specific actual research questions being used more explicitly. As Markku Rummukainen emphasizes 
in a recent paper, "it is necessary to further refine the question of added value of regional climate modeling to added value to 'what' and 'where'" (2016, p. 155). While some modelers use quantitative metrics to decide whether there is added value, others use qualitative methods such as visual comparison, complexity, or detailed process-level analysis (Di Luca et al. 2015; Bukovsky et al. 2013, 2015a). Thus, we argue, the intended meaning of added value needs to be specified fully in each case. Racherla et al.'s approach asks the specific research question about climate change measures, and indicates there is little added value to large-scale regional temperature and precipitation climate change measures in the regional model (Figure 4).

Figure 4: Racherla et al. Research Question

Racherla et al. Research Question (RQ): Did RCMs add value by improving modeling of large-scale regional temperature and precipitation climate change measures? Possible and Responsive Answers:

A: Yes, ....

A: No, RCMs did not add value because they did not improve [very much] our modeling of large regional temperature and precipitation climate change measures

The usual approaches used by most regional climate modelers are quite different, and their research questions typically use the RCMs to model mean climate and extremes for a given historical period of time. They find positive uses for RCMs (Figure 5).

Figure 5: Usual RCM Research Question (RQ):

Usual RCM Research Question (RQ): Do RCMs add value by improving our modeling of mean climate and extremes for a given historical period of time?

Possible and Responsive Answers:

$\boldsymbol{A}$ : Yes, RCMs add value by improving our modeling of mean climate and extremes for a given historical period of time

B: No, ...

As is now highlighted, Racherla et al. are using RCMs for rather different research questions and purposes than they are usually used (See NRC 2012 for other common uses). And while Racherla et al. admitted that RCMs added value in the latter types of cases (e.g., in Figure 5), they found that RCMs did not add value in the atypical contexts they focused on, i.e., large regional temperature and precipitation climate change measures (e.g., in Figure 4). That is, Racherla acknowledged RCMs' ability to add value in climatology over limited world regions, e.g., acknowledging some successes for NARCCAP, for example, but they instead focused on the modeling of climate change within these regions. And remember that the science writer, Kerr, composed a negative piece about regional climate models based on the Racherla et al. paper that helped ignite this confrontation among modelers, despite the fact that Racherla et al. were not evaluating regional climate models in the usual way.

In sum, in the above incident with Racherla et al. and with Kerr, as well as in other cases, there seems to be a miscommunication between the regional climate modeling community and parts of the global modeling — and also the general science-communities about what the representational and epistemic purposes, and pragmatic goals and achievements of regional climate modeling really are, and therefore what their added value might be. These global modelers sought improvements in large regional precipitation and temperature climate change measures, that is, more precise or accurate 
measurements of their sought-out variables, while the regional modelers are offering something different, in the higher resolution details of the regional causal processes, climate and weather systems, that are not fully available at that level of detail at the global climate model level. Thus, for many of the regional modelers, it is an issue of complementarity, rather than competition or increased accuracy of larger-scale variables (in both space and time; e.g., first order mean seasonal bias over continents), with the global climate models. Hence, we have Laprise writing that the Shindell et al. statement is "at variance with the stated goal" of regional climate modeling (Laprise 2014, p. 3881).

For example, the regional modelers' focus is often on improved simulation of precipitation and its variability and extremes; this is a key variable for them because some of the most important societal impacts of climate change will likely result from changes in precipitation, especially of extremes. In addition, pragmatic and social values to keep communities safe from flood and drought, as well as forest fire risks, may be in play.

What is the nature of the conflict or disagreement here? Do the global modelers really want to say that they do not desire the detailed information that would be needed for the regional and city planners? Not at all. But from the outside, there seems to be a basic difference of modeling goals or aims occurring here, including representational aims posed in the form of distinct research questions (Lloyd 2015a; Weisberg 2006; van Fraassen 2004, 2008). ${ }^{4}$ And there may also be a difference in estimation of what the regional climate models are capable of doing, although often this is just another way to say that the research questions vary. In our view, it is best to understand much of this in terms of different research questions that are being pursued; added value is being evaluated differently in tandem with those research questions. It is important to remember, though, that differences between global and regional modelers are only matters of degree. Nonetheless, there remains less communication of know-how across the communities than would be desired for maximum benefit to both communities (Giorgi 2019, p. 5716). Moreover, parts of the modeling community are pursuing models that utilize variable resolution configurations of GCMs.

We can tie in major goals of representation and epistemic issues, involving large regional or global mean climate change measures, especially, and improvements in those measures, being sought, in the global models, in contrast with pragmatic and representational goals in RCMs, where these models are used for practical community planning purposes more or less directly by users in conjunction with the regional climate modelers who facilitate such applications, for example, at NCAR where we work. The contrast is that global models or GCMs have much less pragmatic application, directly, and in fact, the RCMs are often the method for applying the knowledge reached through the GCMs. It should be remembered that statistical downscaling, which is much cheaper computationally, is also a major means by which results of global climate model simulations are rendered more pragmatically useful (Kotamarthi et al. 2016).

Returning to the criticisms of RCMs, the critique of Risbey and Stone detailed in Sect. 4 was offered in 1996, and may be considered too old to concern us, but Risbey's

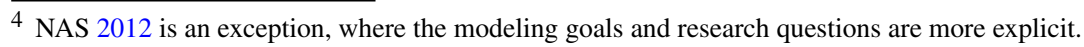


opinion remained negative 15 years later, when he and Terrence O'Kane complained of further weaknesses in the RCMs. Generalizing, Risbey and O'Kane wrote: “The inability of GCMs to adequately represent the key dynamical instabilities in the ocean must degrade the simulation of regional climate in these models" (Risbey and O' Kane 2011, p. 763). Moreover, "[a]ny regional scale variable that depends on the dynamics and details of the circulation (e.g. wind, rainfall) will not be reliably simulated" (Risbey and O'Kane 2011, p. 764). Note the reference to precipitation, here. In sum, Risbey and $\mathrm{O}$ 'Kane conclude in this section:

Downscaling may have some utility in situations and regions where the flow changes are more robust (Held and Soden 2006) or where there is a predictable interaction with topography. However, for many regions... it is unclear what the utility of downscaling is. (2011, p. 765)

Analyzing the disagreement between regional climate modelers and Risbey and colleagues' views of the added value by RCMs is a bit complex (see Risbey et al. 2002, 2005). Before we do so in more detail, let us consider the recent Focus Article in WIREs on added value by Rummukainen. He first characterizes 'added value' very generally: "'Added' typically refers to information that is not directly present nor easily, or at all, retrievable from the GCM...The 'value' signifies that the additional information is credible and/or has utility" (2016, p. 146). We would emphasize the generality of what Rummukainen is saying here; Rummukainen further noted, in a very general claim, that "[i]t is well established that regional climate modeling leads to quantifiable and realistic added information when compared to their driving GCM outputs" (2016, p. 146). But, like Di Luca et al. (2015), he also cautions that the various efforts to quantify or give a precise formula for added value in the literature have failed to capture all of its manifestations; some of the added value, he says, must be considered subjective in each case, "such as what separates 'good enough' from 'not good enough', and performance-based weighting of ensembles (which (sub)sets of models and/or model metrics to choose?)" (2016, p. 148). In addition, there are other reasons for not wanting to quantify added value, e.g., it is unclear how different types of values (such as explanatory vs. pragmatic values) could be quantified in such a way that the two types could be directly compared.

Nevertheless, there are several key components that appear reliably in cases of added value, under Rummukainen's analysis, such as increasing resolution, when accompanied by appropriate changes in parameterization of subgrid-scale processes, along with representation of the physical basis of atmospheric processes from the simulations (2016, pp. 148-149; Dudhia 2014; Wang et al. 2013). ${ }^{5}$ Similarly, on DiLuca et al.'s recent analysis of the key choices in design of experimental setups influencing resulting added value, they emphasize boundary conditions, what the model nesting approach is (concerning how large a jump in resolution is being attempted), and robustness of the results, whether a single result, a multi-member ensemble using a single

\footnotetext{
5 With regard to climate change itself, rather than the usual modeling of present day climate, RCMs can give different information than the driving GCM, but Mearns et al. showed that an RCM provides a more physically realistic simulation of regional climate change trends than its driving GCM (2013). This was one of many RCMs that provided physical processes not resolved at the GCM level, to provide climate change projections for specific contexts, parameters, and regions (Rummukainen 2016, pp. 151-153).
} 
model, or a multi-model ensemble (2015, p. 16). This means that the added value depends strongly on how well physical processes are parameterized (modeled) and how well adapted they have been made to the higher resolution model (Di Luca et al. 2015, p. 17).

With these views in mind, let us look at the simple research question, in conjunction with Risbey and colleagues' answers.

Figure 6: Risbey and O'Kane's views on added value

Simple RQ: Do RCMs have Added Value?

A: No, not in all cases, and it is unclear what the value of downscaling is in many regions (Risbey and O'Kane 2011)

A: Yes, but only where there is predictable interaction with topography, and where flow changes are robust. But not in cases of wind or rainfall (Risbey \& O'Kane 2011)

There is a quite different response from the regional climate modelers, and let us consider it as a contrasting answer here:

Figure 7: Regional climate modelers' views vs. Risbey and O'Kane's views Simple RQ: Do RCMs have Added Value?

$\boldsymbol{A}$ : No, not in all cases, and it is unclear what the value of downscaling is in many regions. And not with rainfall (Risbey \& O'Kane 2011)

A: Yes, but regional climate modelers never claimed all cases and all regions, mostly in areas of complex topography and flow changes, and where studying fine scale precipitation or storms (Mearns et al. 2013; Bukovsky et al. 2017; Di Luca et al. 2013, 2015; Laprise 2014; Giorgi et al. 2016; Giorgi 2019, etc.)

Thus, the regional climate modelers directly disagree with Risbey and O'Kane about modeling precipitation and storms, as reliable in RCMs. And Mearns, Bukovsky, DiLuca, Giorgi, and Laprise think that understanding of global climate processes will increase with regional modeling, as the regional models represent the causal basis of upper level variables and processes, and can predict some of those processes and variables under certain conditions.

But as Risbey and O'Kane conclude their 2011 paper, they are most concerned about how the end-users in the impacts community are perceiving what they see as the unsatisfactory epistemic situation with the regional climate models: "The question then is are we successfully communicating the ignorance underlying regional climate change projections (where it exists) to the impacts community that use these projections?" (Risbey and O'Kane 2011, p. 765). They write that "[t]he question is important because a considerable fraction of the total research effort on climate change is devoted to assessing impacts on the basis of regional projections (Parry et al. 2007)" (2011, 765). And these are projections that, to them, are based on inadequate science.

This pessimistic assessment is on a par with the Kerr critique of added value of the RCMs, and Risbey's overall reasoning needs to be examined closely. This set of objections seems to err in thinking that the large and synoptic scale flow in the GCMs is often mistaken (Risbey and Stone 1996; Risbey and O'Kane 2011), whereas today's GCMs often do well with large scale flow, except in relatively rare cases involving large-scale blocking patterns, or related phenomena, although they have 
modeled ENSO more adequately (Davini and D'Andrea 2016; Bellenger et al. 2014; Haarsma et al. 2016; Roberts 2018; Schaffrey et al. 2009; Masson et al. 2012). In simulating the temperature accurately at the regional scale, this allows other variables to also be more accurately simulated, as well as improving the simulation of the atmosphere itself downstream. While it is certainly true that RCMs can inherit errors from the GCMs, as they did in the case study of Risbey and Stone of the Sacramento Basin in 1996, this does not mean that regional simulations in general and broadly speaking do not add value. It is a false generalization, apparently primarily from one case study, to assert so (see Giorgi 2019). In addition, downscaling does not simply sharpen up precipitation, but we are also able to choose better physical representations for model processes, that is, a model's physical parameterizations, specifically for a region of interest; it is not just that the terrain is better resolved. The precipitation may be more appropriately or realistically and causally represented, as well, as we see with Bukovsky et al. (2017).

However, we must say that Risbey is right that false certainty based on higher precision and higher resolution is an issue in regional climate modeling, and it has been discussed in weather forecast modeling since its inception. We described this under the heading of "Useless Added Value", with the North American Monsoon example, above in Sect. 2, where it was "useless" because the inputs into the models were faulty for one reason or another. The Risbey and Stone (1996) modeling of the Sacramento Basin is another perfect example of "Useless Added Value."

Here in Figure 8 is the situation with the current answers to the added value question on both sides, taking much of the present state of affairs into account. We have the general answer "no" in terms of large-scale climate change measures, and "yes" in terms of causal processes and understanding, as well as impacts.

\section{Figure 8: Both sides}

\section{RQ: Do RCMs have Added Value?}

$A$ : No, not so much for helping model large regional temperature and precipitation climate change measures (although there are cases of this)

A: Yes, in many cases of impacts of global change on regions in terms of local temperature, water supplies, floods, and fire risk, and in better resolving causal processes that underlie the global variables.

But by directly comparing the different detailed research questions pursued by different parties in the debate about added value, we can see more clearly what the arguments are actually about.

Compare this research question from the global modelers:

\section{Figure 9: Global modelers}

$\boldsymbol{R Q}$ : Do RCMs have added value to help model large regional temperature and precipitation climate change measures?

A: No, large scale climate change measures are not their strength.. .

A: Yes, ...

... with the research questions from the regional modelers, here:

\section{Figure 10: Regional modelers}


$\boldsymbol{R Q}$ : Do RCMs have added value in understanding and resolving with greater detail causal processes and regional impacts?

A: Yes, RCMs help in understanding impacts in terms of local temperature, water supplies, floods, and fire risk \& in understanding and resolving climate causal processes that underlie larger scale processes in greater detail

A: No....

And you see why the regional climate modelers often answer "yes" to their added value question.

In addition, bare economic interests are sometimes exposed, as was revealed in the Risbey quote above. In this section we discussed the examples relating to Racherla et al., and Risbey and colleagues, which show how added value can be denied to regional climate models even when they do, in fact, add value along certain lines. In some cases, when asked to do tasks for which they are not designed, they fail to add value, for which they are faulted, and claimed not to add value anywhere or at all. These are, as we can see, unfair tests, which was not communicated clearly to the related parties because the research question was obscure in each case. This is often an example of missed communication based on conflicting research questions, which obscures the added value of regional climate models, and demotes their competence. We are now in an informed position to consider some available definitions of added value.

\section{Definitions of 'added value'}

There are a variety of goals and purposes that can be aspired to when practicing dynamical downscaling using RCMs, but the predominant ones involve using them to represent the addition or inclusion of features that are not explicitly resolved by coarse-scale general circulation models or GCMs. Thus, RCMs usually involve a new goal or purpose of representation in an alternative or complementary fashion; global models cannot perform yet on a comparable level of detail or function, although they likely will be able to, soon, for some variables and processes (NAS 2012; Skamarock et al. 2012).

What do we get, as an advantage or bonus, when we make use of a regional climate model? What is added to our repertoire of representations? What is the added value of RCMs? Let us look at some definitions. The UN's Intergovernmental Panel on Climate Change defined "added value" equivocally, at first defining it explicitly in terms of accuracy:

RCMs are regularly tested to evaluate whether they show improvements over global models..., that is, whether they do indeed 'add value'. In essence, added value is a measure of the extent to which the downscaled climate is closer to observations than the model from which the boundary conditions were obtained. (2013 WGI AR5, 815; emphasis added)

But observations come in all sorts of temporal and spatial scales, and for many different variables, so it is extremely unclear what is being referred to here. Which variables 
need to be closely described or matched in order for success in added value to be attained, in terms of being "closer to observations"? The further discussion of added value is less ambiguous:

... RCM fields are, however, richer in spatial and temporal detail. Indeed, the added value of RCMs is mainly expected in the simulation of topography influenced phenomena and extremes with relatively small spatial or short temporal character (emphasis added)

Or, as the IPCC authors put it:

[T] here is high confidence that downscaling adds value to the simulation of spatial climate detail in regions with highly variable topography (e.g., distinct orography, coastlines) and for mesoscale phenomena and extremes. (IPCC Ch 9, 2013, 815; their emphasis; emphasis added)

Regional downscaling, as presented here through a variety of RCMs, is then analyzed as "complementary to results obtained directly from global climate models" (IPCC 2013, 815; emphasis added).

That is, here, the IPCC authors note that the regional models are not usually competing representations to the global ones, but complementary ones. They model different processes, at different levels of organization, that is, the more detailed, causal process levels. It is very significant that in addition to the original IPCC definition, concerning increased accuracy and closeness to observations, another, distinct definition of added value is being utilized by the IPCC authors, one in terms of complementarity of the RCM to the GCM scale models.

\subsection{Complementarity and causes}

In our project on the added value of the RCMs, we are carefully investigating this crucial complementary role of representations, an underexplored aspect of modeling that deserves a great deal more serious attention and analysis than it has received so far, both in philosophy of science and in analysis of climate modeling.

Our analysis so far indicates that:

1. There is no context-independent definition of added value; what counts as added value depends on what you want to use the models for (see Giere 2004; van Fraassen 1980, 2004; Risbey et al. 2005; Parker 2006). Thus, different modelers are asking different research questions, and thus evaluating added value differently. Different research questions assume different specific definitions of added value, as we saw with Racherla and Laprise.

2. Secondly, there is a difference in emphasis between the relationship of increased accuracy, and complementarity of models.

For example, we can see that the Racherla et al. paper concerned increased accuracy of the large regional temperature and precipitation variables of climate change, while Laprise was advocating a complementary modeling role for RCMs, thus producing a clash between these authors concerning the proper roles of regional climate models and their relationship to global models. It is no wonder that they disagreed about the 
proper research question to pursue for added value, and the answers to the question of whether there was, indeed, "added value"; they were asking and answering distinct questions.

Finally, continuing with the numbering introduced above, there are three major types of components that need to be examined in evaluating added value: Temporal Scale; Spatial Scale; and Causal Processes:

3. Temporal Scale: Because the GCM computational time step is larger than that of typical simulations with regional models, output data at longer intervals is more meaningful, while in RCMs the shorter computational time step means it can output meaningful data at a higher frequency. Therefore, RCMs can be used to output meaningful sub-hourly to hourly data easily (depending on computation time step), whereas in GCMs output data at frequencies this high may not be as meaningful. Output frequency of data, and of stored output data, is also often higher in RCMs compared to GCMs, not just because the computational time step may allow for this, but because data storage constraints may be more relaxed in regional simulations compared to analogous global simulations.

4. Spatial Scale: for example, RCMs may span 2-, 5-, 10-, or 25- or 50-km scales, while a typical GCM grid-box spans 100-300 km, while some have grid-cells of 50or 25-. Trade-offs are made with length of simulations, size of domain for RCMs, and complexity of the model. But the question is the tradeoff of length of simulation and resolution, the size of the initial value ensemble, the number of different regional and/or global models used, as well as multiple emission/concentration scenarios, given a certain amount of available computer resources. For the 'standard' simulations for CMIP6, for example, the typical resolutions for 150-year simulations for multiple concentration scenarios is about $50-100 \mathrm{~km}$ for fully coupled atmosphere/ocean models.

5. Causal Processes: Processes which are resolved at different time and space scales in RCMs and GCMs, from regional jets to storms and rainfall, appear in less detail in the large grid-size GCMs, if at all, depending on the scale of the process. ${ }^{6}$

In sum, on our analysis, after establishing the context of a situation of added value, the research question being pursued needs to be specified, which must incorporate the major question, "does the case of added value primarily emphasize increased accuracy or complementary modeling?" In addition, three types of components need to be approached and examined in evaluating a research question concerning added value: temporal and spatial scales and causal processes (see Di Luca 2011). We first ask, what is the context and research question at stake, then we might move back to the alternative complementary role for RCMs, which offers a different set of epistemic, representational, and pragmatic values than global models, and a fresh challenge for any philosophy of science account.

Specifically, we can address the issue of added value in the context of a research question, as follows: does the RCM offer a complementary representation of variables, parameters and processes, such as detailed rainfall, storms, or orography, to the GCM description of the state and progress of the climate? Such complementarity is not

\footnotetext{
6 There may be less emphasis among seasonal predictors on this causal component of modeling. (Thank you to an anonymous reviewer for highlighting this feature.).
} 
usually on any list of epistemic or representational values of models in the philosophy of science, although it is not precisely clear why. What role should complementarity be understood as playing?

One avenue is to explore the possibility of a pluralist stance, that is, "the possibility that, in some cases of investigation, there will be a plurality of accounts that cannot be integrated with one another," according to Kellert and Longino (2006). It seems that climate modelers likely construct different models depending on their interests, and which aspects are considered the most relevant depends on the investigator(s). Even under a non-pluralist account such as Peschard and van Fraassen's, the question arises

...whether the different models that are produced,... can 'peacefully' coexist, either in the way different models serving different purposes can do so, or in that they can be somehow unified as parts of a larger account (Peschard and van Fraassen 2014, p. 8).

Thus, we may consider whether the GCMs and RCMs may peacefully coexist, in an added value situation, by serving different purposes, like commensalism in ecology, where they do not do any harm to one another, or may be unified, by being parts of a larger account of the climate, which might be analogous to mutualism, another form of symbiotic relationship, wherein both parts benefit from the mutual relationship, and do not harm one another.

This leaves another, more perplexing possibility, wherein one model, such as an RCM, gives results, e.g., precipitation results, that are inconsistent with the GCM precipitation results, as has happened (Bukovsky et al. 2015a, b, 2017; Giorgi et al. 2016). These differences rely on the physics of the RCM producing a more plausible and credible change in precipitation, while maintaining the large-scale climate changes from the GCM. Thus, this would not be a relationship of pure complementarity, but rather partial conflict, wherein the RCM undermines certain results given by the GCM, while also using the GCM's large-scale results to drive the RCM. Thus, these models appear to be unified in some way in their construction, but cannot be fully compatible with one another due to the conflict in detailed representation of processes (see Peschard and van Fraassen 2014; Giere 2006; Kellert and Longino 2006; see Parker 2006 for discussion of climate model pluralism). These cases might be better understood under the IPCC's first definition of "added value", i.e., the "closer to observations" or generally "more accurate" definition. That is, because the RCMs here give better resolved (more detailed) representations of the precipitation in these systems, they compete with the GCM descriptions, but only in the sense that they are more accurate descriptions that better track the observed values.

This is perhaps another way of asking whether the "complementarity" interpretation of added value might be the most comprehensive and fruitful philosophically; it is another question whether it may also be the best scientifically, given the contextsensitivity of the term, and the possibility of conflict sketched above. We resolve this potential conflict through mobilizing both definitions from the IPCC of added value.

We discussed above how the relationships between the global and regional climate models can affect RCM outcomes. We emphasized that inaccurate boundary conditions from GCMs, while they can sometimes be corrected at the regional level, still often lead to problems in RCM outcomes. The other case is when the GCM does well, and 
everything is complementary and as hoped for, when the finer scale adds accurate detail to the system. This is what is aimed for in the good cases of downscaling RCMs, and it sometimes works this way. In the new simulations in the North American component of the world-wide regional modeling program, CORDEX, the span of the GCMs turned out to represent a good range of climate sensitivity. The variable resolution models MPAS and ACME (Sakaguchi et al. 2015, 2016; Ringler et al. 2008; Fowler et al. 2016) would be another case of when the lower and higher resolution parts of the model would coexist to form a unified whole.

It is also crucial, in considering added value, that RCMs better represent the causal processes underlying some of the values represented in the GCMs. Understanding these causal processes is often valuable, for pragmatic reasons and community goals, such as planning for water management, agriculture, flood control and forest fire management and control. This is because causal understanding of these climate and weather processes is helpful, if not essential, for their management. As such, the regional climate models are meeting a set of pragmatic purposes for the modelers and users of the models (Di Luca et al. 2015).

In the case of pragmatic uses, the counterfactual to causal understanding of climate and weather processes using RCMs is also a relevant example of their added value in climate change research. That is, RCMs are used to simulate what one specific, observed weather event (e.g., a flood, drought, or hurricane) might look like in a future climate or a range of future climates following the physical storyline approach (e.g., Shepherd et al. 2018, and examples contained therein). As explained in Shepherd et al. (2018), a storyline is "a physically self-consistent unfolding of past events, or of plausible future events or pathways. ... As no a priori probability of the storyline is assessed, it is not a prediction. Emphasis is placed instead on understanding the driving factors involved and the plausibility of those factors (or of changes in those factors)." In this application, RCMs are often forced with a reanalysis or similar product for an event that took place in the historical climate, and then the reanalysis boundary conditions are perturbed (i.e., the causal processes are perturbed) to examine what the event might look like in different future climates (sometimes using climate changes from GCMs applied using a pseudo global warming methodological approach-e.g., Rasmussen et al. 2011). RCMs are ideal tools for storyline type studies, as an event is often very regional in nature and high-resolution (on the order of 1-4 km) is often needed to simulate the event with greatest fidelity; therefore, making an RCM a computationally and scientifically logical choice.

These pragmatic and community values and uses rely on the models meeting epistemic standards of a minimal sort, that is, the RCMs' parameters and parameterizations as well as output variables must satisfy reasonable epistemic values. This is one place where the potential added value of the RCMs lies. Relative credibility of RCMs increases with a variety of strengths documented in the literature (Mearns et al. 2013). Reviewing these aspects of epistemic credibility as presented in Giorgi et al. (2016), they include consistency across models using different convective schemes, across future time slices and with observed trends, statistical significance of the signals, and identification of an underlying process, as well as robustness across a variety of variables. 
We can see these ideas being cashed out within DiLuca's definition of 'Added Value 1': RCMs added value in climate variability in scales that are not explicitly resolved in GCMs simulation (Di Luca 2011). A necessary condition for Added Value1 is that the RCM must simulate fine-scale details that contribute to climate statistics in a manner that is "not negligible" (Di Luca 2011). Thus, the RCMs' role is at least partly complementary to the GCMs', in a manner that is not trivial. One of the functions of RCMs in most cases, is to better resolve causal processes underlying the GCMs' climate. Moreover, at very high resolutions, e.g., $2 \mathrm{~km}$, the RCMs actually explicitly resolve processes that are only parameterized in the GCMs. Convection is the clearest example of this (Westra et al. 2014; Kendon et al. 2014, Prein et al. 2015).

One of the most vital functions of RCMs is to better articulate and understand the causal processes underlying the GCMs' climate (Mearns et al. 2014; Bukovsky et al. 2017). The increase in understanding of the climate system generated through application of the RCMs is thus central to the notion of added value (e.g., Bukovsky et al. 2017; Mearns et al. 2014; Giorgi et al. 2016), where "understanding" encompasses deeper knowledge of the fine-scale causal processes underlying climate processes and dynamics (Newman 2012). We can thus see that RCMs can add value by helping us understand these causal processes that underlie the global models. By asking the research question in the right way, this can be made clear.

\section{Figure 11}

$\boldsymbol{R} \boldsymbol{Q}$ : Do RCMs add value, given the large scale GCM climate, by increasing understanding of the finer scale causal processes?

A: Yes, RCMs can increase understanding of causal processes by better resolving rain shadows, storms, and fine-scale precipitation which in turn better reflect global climate phenomena

$\boldsymbol{A}$ : No, they do not add value, because they do not increase understanding of the fine-scale causal processes

In sum, the epistemic credibility, representative value, and pragmatic value of RCMs may rest on our grasp of the model's causal processes, which can give us confidence for projections into the future, just as we saw in the snow and albedo case in the Rocky Mountains and High Sierra, the precipitation in the Southern Great Plains, and the snow in the high Alps. This is all added value given by regional climate models.

Or consider the "Potential Added Value" of RCMs as has been defined by Alejandro DiLuca (2011). The basic idea is that added value can only arise if there is nonnegligible fine-scale information, which can then be used to quantify the relative influence of fine scales in climate statistics "as a proxy for estimating the Potential Added Value (PAV) of RCMs" (DiLuca 2011, xxi dissertation abstract). This is done both for temperature and for precipitation, by using a decomposition technique to separate atmospheric variables in several temporal and spatial scales, which is then used to estimate the contribution to the climate statistics coming from those smallscales represented by RCMs but absent in the driving data (from the GCMs). Using our schema above, this presents several types of evaluation and information: First, in terms of scales - fine-scales of both spatial and temporal types-plus second, in terms of the processes that result in the simulation of temperature and precipitation. We can see clearly that DiLuca is calculating his (PAV) using these basic components in our 
analysis. This definition would include the case of snow in the Rockies and the High Sierra, as well as the Southern Great Plains and high Alps cases discussed above, and other successes of RCMs providing detailed processes.

Di Luca et al. (2015) also propose a "conjectural" added value, to signify added value "in those climate statistics for which no observational estimations are available but that are either firmly supported by theoretical considerations or by a number of studies realized under similar circumstances" (Di Luca et al. 2015, p. 14). This can be used, for example, to argue that representing hail at a convection-permitting scale comprises an added value, even if there are few opportunities to empirically verify this claim.

It is clear that Di Luca et al. (2015) do not want to advocate a formal definition, or formula, of added value. In the conclusion of their recent paper on added value, they wrote:

It is from local interactions-defined by differential equations-that physics sets the conditions for the emergence of weather and climate variability at all spatial and temporal scales. The great story behind climate models is that they reproduce with surprising precision this causal chain. We believe that more meaningful added value may be found by exploring conditions conducive to particular weather and climate events than by focusing on simple statistics. (2015, p. 18)

But we find that commitment to a single formal definition is not needed, while the handful of definitions that are available are all useful in their contexts.

\section{Conclusions}

One additional thing that is at stake: Where are the research dollars going? Are they going to fund global climate modeling with its investigation of large-scale climate change and global climate warming? Or are they also going to regional climate modeling and the modeling immediately relevant to the impacts of global warming on local regions and communities in terms of water supplies, agriculture, floods, and fire risk? Because results from regional climate models are actively used by regional planners, in addition to statistical downscaling techniques, they stand in a rather different relation to policy than those from global models. It is something that we must consider when answering the question of whether regional climate models add value, and it is precisely here that RCMs' overall value has been challenged.

Different interests are driving the differing research questions asked by the regional and global modelers, which must be taken into account in their answers to a given question about added value. We hope to have shown in this paper that added value must be approached in relation to several carefully definable issues, including the precise research question and its context; whether the modelers are seeking primarily improved accuracy of a given variable, as we see in conflicting regional and global models of a given variable, or rather, complementarity of models; and finally, the temporal, spatial, and causal orientations of the models in question. Taking these factors into account often yields a more complementary view of the relationship between global 
and regional modeling that can be fruitful and tolerant, as well as being scientifically more precise and accurate.

We have discussed how regional climate models can be understood as adding value in Sect. 2, where we also introduced pragmatic, epistemic, and social values of regional climate models. We have analyzed some claims that RCMs do not add value, in Sects. 3 and 4. We have emphasized that the primary issues in such claims often arise from different research questions being pursued by the critic and the regional climate modeler. We have analyzed research questions throughout, to make more precise many of these criticisms and differences among modelers and positions. We addressed key definitions of added value in Sect. 5, and discussed the core issues of complementarity and causes. In sum, we found that judgements that regional climate models do not add value are often based on misunderstandings or disagreements about the research question being pursued or false generalizations from deficient models, rather than being based, as appears at first blush, on lack of strength of the RCMs themselves, although there is always room for improvement.

In the context of regional climate models used for simulating projections of climate change, there are a number of 'standard' uncertainties, most of which are shared with global models. These include the uncertainties regarding future trajectories of greenhouse gas emissions and concentrations, uncertainties related to the global models (imperfections in modeling the climate system), and the internal variability of the climate system (Hawkins and Sutton 2009). The additional uncertainties related to the regional climate models themselves may be seen as part of the uncertainty related to modeling the climate system. This includes the selection of different methods for modeling components of the climate system (i.e., use of different RCMs), choice regarding the domain size and location, and means of assimilating the lateral boundary conditions. The application of downscaling usually increases the overall uncertainty.

Acknowledgements Dr. Bukovsky was supported by the NCAR Weather and Climate Impacts Assessment Science Program and Regional Climate Uncertainty Program managed by Dr. Mearns, funded by NSF under the NCAR cooperative agreement. Dr. Mearns was funded by NCAR, which is funded by the NSF. Dr. Lloyd would like to thank Ryan O'Loughlin, Daniel Lindquist, Stuart Gluck, and Chris ChoGluck for their useful assistance, as well as audiences at the University of Chicago and the American Philosophical Association, Eastern Division, where this work was presented. She is indebted to Douglas Nychka for aid in studying and working at NCAR, as well as to the NSF on Grant \#SES-1754740.

Open Access This article is licensed under a Creative Commons Attribution 4.0 International License, which permits use, sharing, adaptation, distribution and reproduction in any medium or format, as long as you give appropriate credit to the original author(s) and the source, provide a link to the Creative Commons licence, and indicate if changes were made. The images or other third party material in this article are included in the article's Creative Commons licence, unless indicated otherwise in a credit line to the material. If material is not included in the article's Creative Commons licence and your intended use is not permitted by statutory regulation or exceeds the permitted use, you will need to obtain permission directly from the copyright holder. To view a copy of this licence, visit http://creativecommons.org/licenses/by/4.0/.

\section{References}

Arritt, R. W., \& Rummukainen, M. (2011). Challenges in regional-scale climate modeling. Bulletin of the American Meteorological Society, 92, 365-368. https://doi.org/10.1175/2010BAMS2971.1. 
Bellenger, H., Guilyardi, E., Leloup, J., Lengaigne, M., \& Vialard, J. (2014). ENSO representation in climate models: From CMIP3 to CMIP5. Climate Dynamics, 42, 1999-2018. https://doi.org/10.1007/s0038 2-013-1783-z.

Benestad, R., Haensler, A., Hennemuth, B., Illy, T., Jacob, D., Keup-Thiel, E., Kotlarski, S., Nikulin, G., Otto, J., Rechid, D., Sieck, K., Sobolowski, S., Szabo, P., Szepszo, G., Teichmann, C., Vautard, R., Weber, T., \& Zsebehazi, G. (2017). Guidance for EURO-CORDEX climate projections data use. https://www.euro-cordex.net/imperia/md/content/csc/cordex/euro-cordex-guidelines-version1.02017.08.pdf. Accessed 8 Aug 2020.

Bukovsky, M. S. (2016). NA-CORDEX simulations of the North American Monsoon. In Presentation. International conference on regional climate-CORDEX. Stockholm, Sweden: WCRP. 18 May 2016.

Bukovsky, M. S., Carrillo, C. M., Gochis, D. J., Hammerling, D. M., McCrary, R. R., \& Mearns, L. O. (2015a). Towards assessing NARCCAP regional climate model credibility for the North American Monsoon: Future climate simulations. Journal of Climate, 28, 6707-6728. https://doi.org/10.1175/ JCLI-D-14-00695.1.

Bukovsky, M. S., Carrillo, C. M., Gochis, D. J., Mearns, L. O. (2015b). Assessing regional climate model simulation credibility for the North American Monsoon. In Reunión Annual 2015, Puerto Vallarta, Jalisco, Mexico. Unión Geofísica Mexicana, SE15-4.

Bukovsky, M. S., Gochis, D. J., \& Mearns, L. O. (2013). Towards assessing NARCCAP regional climate model credibility for the North American Monsoon: Current climate simulations. Journal of Climate, 26, 8802-8826. https://doi.org/10.1175/JCLI-D-12-00538.1.

Bukovsky, M. S., McCrary, R. R., Seth, A., \& Mearns, L. O. (2017). A mechanistically credible, poleward shift in warm-season precipitation projected for the US Southern Great Plains? Journal of Climate. https://doi.org/10.1175/JCLI-D-16-0316.1.

Christensen, J. H., Kanikicharla, K. K., Aldrian, E., An, S. I., Cavalcanti, I. F. A., de Castro, M., Dong, W., Goswami, P., Hall, A., Kanyanga, J. K., \& Kitoh, A., (2013). Climate phenomena and their relevance for future regional climate change. In Climate Change 2013 the Physical Science Basis: Working Group I Contribution to the Fifth Assessment Report of the Intergovernmental Panel on Climate Change (pp. 1217-1308). Cambridge University Press.

Ciarlo, J. M, Coppola, E., Fantini, A., Giorgi, F., Gao, X., Tong, Y., Glazer, R. H., Alavez, J. A. T., Sines, T., Pichelli, E., Raffaele, F., Das, S., Bukovsky, M. S., Ashfaq, M., Im, E.-S., Nguyen-Xuan, T., Teichmann, C., Remedio, A., Remke, T., Bülow, K., Weber, T., Buntemeyer, L., Sieck, K., Rechid, D., \& Jacob, D. (2020). A new spatially distributed added value index for regional climate models: the EURO-CORDEX and the CORDEX-CORE highest resolution ensembles. Climate Dynamics, accepted pending revision.

Davini, P., \& D’Andrea, F. (2016). Northern Hemisphere Atmospheric Blocking Representation in Global Climate Modeling: Twenty Years of Improvements? JCLI. https://doi.org/10.1175/JCLI-D-16-0242. 1.

Denis, B., Laprise, Rene, Caya, Daniel, \& Cote, J. (2002). Downscaling ability of one-way nested regional climate models: The Big-Brother Experiment. Climate Dynamics, 18(8), 627-646.

Di Luca, A. (2011). A framework to study the potential benefits of using high-resolution regional climate model simulations. Thèse. Montréal (Québec, Canada), Université du Québec à Montréal, Doctorat en sciences de la terre et de l'atmosphère.

Di Luca, A., de Elía, R., \& Laprise, R. (2012). Potential for added value in precipitation simulated by highresolution nested Regional climate models and observations. Climate Dynamics, 38(5-6), 1229-1247. https://doi.org/10.1007/s00382-011-1068-3.

Di Luca, A., De Elía, R., \& Laprise, R. (2013). Potential for added value in temperature simulated by high-resolution nested RCMs in present climate and in the climate change signal. Climate Dynamics, 40(1-2), 443-464.

Di Luca, A., de Elia, R., \& Laprise, R. (2015). Challenges in the quest for added value of regional climate dynamical downscaling. Current Climate Change Reports, 1, 10-21.

Di Virgilio, G., Evans, J. P., di Luca, A., Grose, M. R., et al. (2020). Realised added value in dynamical downscaling of Australian climate change. Climate Dynamics. https://doi.org/10.1007/s00382-020-0 $5250-1$.

Dudhia, J. (2014). A history of mesoscale model development. Asia Pacific J Atmos Sci, 50, 121-131. https://doi.org/10.1007/s13143-014-0031-8. 
Fowler, L. D., Skamarock, W. C., Grell, G. A., Freitas, S. R., \& Duda, M. G. (2016). Analyzing the Grell-Freitas convection scheme from hydrostatic to nonhydrostatic scales within a global model. Monthly Weather Review, 144(6), 2285-2306. https://doi.org/10.1175/mwr-d-15-0311.1.

Giere, R. (2004). How models are used to represent reality. Philosophy of Science, 71, 742-752.

Giere R. N. (2006). Perspectival pluralism. Scientific pluralism, 19.

Giorgi, F. (2019). Thirty years of regional climate modeling: Where are we and where are we going next? JGR Atmospheres, 124, 5696-5723.

Giorgi, F., \& Mearns, L. O. (1991). Approaches to the simulation of regional climate change: A review. Reviews of Geophysics, 29(2), 191-216.

Giorgi, F., Torma, C., Coppola, E., Ban, N., Schar, C., \& Samot, S. (2016). Enhanced summer convective rainfall at Alpine high elevations in response to climate warming. Nature Geoscience Letters, 9, 584-590. https://doi.org/10.1038/NGE02761.

Gutowski, W. J., Jr., Ullrich, P. A., Hall, A., Leung, L. R., O’Brien, T. A., Patricola, C. M., et al. (2020). The ongoing need for high-resolution regional climate models: Process understanding and stakeholder information. Bulletin of the American Meteorological Society, 101, E664-E683. (in press).

Haarsma, R. J., Roberts, M. J., Vidale, P. L., Senior, C. A., Bellucci, A., Bao, Q., et al. (2016). High resolution model intercomparison project for CMIP6. Geoscientific Model Development, 9, 4185-4420.

Hawkins, E., \& Sutton, R. (2009). The potential to narrow uncertainty in regional climate predictions. Bulletin of the American Meteorological Society. https://doi.org/10.1175/2009BAMS2607.1.

Held, I. M., \& Soden, B. J. (2006). Robust responses of the hydrological cycle to global warming. Journal of climate, 19(21), 5686-5699.

Intergovernmental Panel on Climate Change (IPCC). (2013). The physical science basis. In Intergovernmental panel on climate change, working group I contribution to the IPCC fifth assessment report (AR5). New York, NY: Cambridge University Press.

Kellert, S. H., \& Longino, H. E. (2006). Scientific pluralism. Minneapolis: University of Minnesota Press.

Kendon, E. J., Ban, N., Roberts, N. M., Fowler, H. J., Roberts, M. J., Chan, S. C., et al. (2017). Do convectionpermitting regional climate models improve projections of future precipitation change? Bulletin of the American Meteorological Society, 98, 79-93. https://doi.org/10.1175/BAMS-D-15-0004.1.

Kendon, E. J., Roberts, N. M., Fowler, H. J., Roberts, M. J., Chan, S. C., \& Senior, C. A. (2014). Heavier summer downpours with climate change revealed by weather forecast resolution model. Nature Climate Change, 4, 570-576. https://doi.org/10.1038/nclimate2258.

Kerr, R. A. (2013). Forecasting regional climate change flunks its first test. Science, 339, 638-638.

Kotamarthi, R., Hayhoe, K., Mearns, L. O., Wuebbles, D., Jacobs, J., \& Jurardo, J. (2020). Downscaling techniques for high resolution climate projections. Cambridge: University of Cambridge Press. (in press).

Kothamarti, R., Mearns, L., Hayhoe, K., Castro, C. L., \& Wuebbles, D. (2016). Use of climate information for decision-making and impacts research: State of our understanding. Washington, DC: Department of Defense Strategic Environmental Research and Development Program.

Laprise, R. (2014). Comment on 'The added value to global model projections of climate change by dynamical downscaling: A case study over the continental US using the GISS-ModelE2 and WRF models' by Racherla et al. Journal of Geophysical Research: Atmospheres, 119(7), 3877-3881. https:// doi.org/10.1002/2013JD019945.2012.

Leung, L. R., \& Qian, Y. (2003). The sensitivity of precipitation and snowpack simulations to model resolution via nesting in regions of complex terrain. Journal of Hydrometeorology, 4(6), 1025-1043.

Lloyd, E. A. (2015a). Adaptationism and the logic of research questions: How to think clearly about evolutionary causes. Biological Theory, 10(4), 343-362.

Lloyd, E. A. (2015b). Model robustness as a confirmatory virtue: The case of climate science. Studies in History and Philosophy of Science, 49, 58-68. https://doi.org/10.1016/j.shpsa.2014.12.002.

Masson, S., Terray, P., Madec, G., Luo, J. J., \& Yamagata, T. (2012). Impact of intra-daily SST Variability on ENSO characteristics in a coupled model. Climate Dynamics, 39, 681-707.

Mearns, L. O., Arritt, R., Biner, S., Bukovsky, M. S., McGinnis, S., Sain, S., et al. (2012). The North American regional climate change assessment program: Overview of phase I results. Bulletin of the American Meteorological Society, 93(9), 1337-1362.

Mearns, L.O., Dominguez, F., Gutowski, W., Hammerling, D., Lettenmaier, D., Leung, R., Michaels, S., Pryor, S., \& Sain, S. (2014). Establishing the value of multiple GCM-RCM simulation programs. In L. Barring, M. Reckermann, \& B. Lund (Eds.), 21st Century challenges in regional climate modelling conference, workshop proceedings (p. 359). Sweden. 
Mearns, L. O., Giorgi, F., Whetton, P., Pabon, D., Hulme, M., \& Lal, M. (2003). Guidelines for use of climate scenarios developed from Regional Climate Model Experiments. DDC of IPCC. http://www. ipcc-data.org/guidelines/dgm_no1_v1_10-2003.pdf. Accessed 8 Aug 2020.

Mearns, L. O., Sain, S., Leung, L. R., Bukovsky, M. S., McGinnis, S., Biner, S., et al. (2013). Climate change projections of the North American regional climate change assessment program (NARCCAP). Climatic Change, 120, 965-975. https://doi.org/10.1007/s10584-013-0831-3.

National Research Council of the National Academy of Sciences (NRC). (2012). A national strategy for advancing climate modeling. Washington, DC: National Academies Press.

Newman, M. (2012). An inferential model of scientific explanation. International Studies in Philosophy of Science, 26, 1-26.

Olesen, M., Christensen, J. H., Kaas, E., \& Boberg, F. (2018). Robustness of high-resolution regional climate projections for Greenland: A method for uncertainty distillation. Climate Research, 76, 253-268. https://doi.org/10.3354/cr01536.

Parker, W. S. (2006). Understanding pluralism in climate modeling. Foundations of Science, 11(4), 349-368.

Peschard, I. F., \& van Fraassen, B. C. (2014). Making the abstract concrete: The role of norms and values in experimental modeling. Studies in the History and Philosophy of Science, 46, 3-10.

Prein, A. F., Langhans, W., Fosser, G., Ferrone, A., Ban, N., Goergen, K., et al. (2015). A review on regional convection-permitting climate modeling: Demonstrations, prospects, and challenges. Reviews of geophysics, 53(2), 323-361.

Qian, J.-H., Ghan, S. J., \& Ruby Leung, L. (2010). Downscaling hydroclimate changes over the Western US Based on CAM subgrid scheme and WRF regional climate simulations. International Journal of Climatology, 30, 675-693.

Racherla, P. N., Shindell, D. T., \& Faluvegi, G. S. (2012). The added value to global model projections of climate change by dynamical downscaling: A case study over the continental US using the GISSModelE2 and WRF models. Journal of Geophysical Research: Atmospheres (1984-2012), 117(D20), 20118.

Rammukainen, M. (2016). Added value in regional climate modeling. WIRES Climate Change, 7, 145-159.

Rasmussen, R., Liu, C., Ikeda, K., Gochis, D., Yates, D., Chen, F., et al. (2011). High-resolution coupled climate runoff simulations of seasonal snowfall over Colorado: A process study of current and warmer climate. Journal of Climate, 24(12), 3015-3048.

Ringler, T., Lili, J., \& Gunzburger, M. (2008). A multiresolution method for climate system modeling: Application of spherical centroidal Voronoi tessellations. Ocean Dynamics, 58(5-6), 475-498. https:// doi.org/10.1007/s10236-008-0157-2.

Risbey, J. S., Lamb, P. J., Miller, R. L., Morgan, M. C., \& Roe, G. H. (2002). Exploring the structure of regional climate scenarios by combining synoptic and dynamic guidance and GCM output. Journal of Climate, 15(9), 1036-1050.

Risbey, J. S., \& O'Kane, T. J. (2011). Sources of knowledge and ignorance in climate research. Climatic Change, 108(4), 755.

Risbey, J. S., \& Stone, P. H. (1996). A case study of the adequacy of GCM simulations for input to regional climate change assessments. Journal of Climate, 9(7), 1441-1467.

Risbey, J., Van der Sluijs, J., Kloprogge, P., Ravetz, J., Funtowicz, S., \& Quintana, S. C. (2005). Application of a checklist for quality assistance in environmental modelling to an energy model. Environmental Modeling and Assessment, 10(1), 63-79.

Roberts, M. J. (2018). The Benefits of global high resolution for climate simulation: Process understanding and the enabling of stakeholder decisions at the regional scale. BAMS. https://doi.org/10.1175/BAMSD-15-00320.1.

Rummukainen, M., Rockel, B., Bärring, L., Christensen, J. H., \& Reckermann, M. (2015). Twenty-firstcentury challenges in regional climate modeling. Bulletin of the American Meteorological Society, 96, ES135-ES138. https://doi.org/10.1175/BAMS-D-14-00214.1.

Sakaguchi, K., Leung, L. R., Zhao, C., Yang, Q., Lu, J., Hagos, S., et al. (2015). Exploring a multiresolution approach using AMIP simulations. Journal of Climate, 28(14), 5549-5574.

Sakaguchi, K., Lu, J., Leung, L. R., Zhao, C., Li, Y., \& Hagos, S. (2016). Sources and pathways of the upscale effects on the Southern Hemisphere jet in MPAS-CAM4 variable-resolution simulations. Journal of Advances in Modeling Earth Systems. https://doi.org/10.1002/2016MS000743.

Schaffrey, L. C., Stevens, I., Norton, W. A., Roberts, M. J., Vidale, P. L., Harle, J. D., Jrrar, A., Stevens, D. P., Woodage, M. J., Demory, M. E., Donners, J., Clark, D. B., Clayton, A., Cole, J. W., Wilson, S. S., Connolley, W. M., Davies, T. M., Iwi, A. M., Johns, T. C., King, J. C., New, A. L., Slino, J. M., 
Slino, A., Steenman-Clark, L., \& Martin, G. M. (2009). U.K. HiGEM: The New U.K. HighOResolution global environment model-model description and basic evaluation. JCLI. https://doi.org/10.1175/20 08JCLI2508.1.

Shepherd, T. G., Boyd, E., Calel, R. A., et al. (2018). Storylines: An alternative approach to representing uncertainty in physical aspects of climate change. Climatic Change, 151, 555-571. https://doi.org/1 0.1007/s10584-018-2317-9.

Shindell, D., Racherla, P., \& Milly, G. (2014). Reply to comment by Laprise on 'The added value to global model projections of climate change by dynamical downscaling: A case study over the continental US using the GISS-ModelE2 and WRF models'. Journal of Geophysical Research: Atmospheres, 119, 3882-3885.

Skamarock, W. C., Klemp, J. B., Duda, M. G., Fowler, L. D., Park, S. H., \& Ringler, T. D. (2012). A multiscale nonhydrostatic atmospheric model using centroidal Voronoi tesselations and C-grid staggering. Monthly Weather Review, 140(9), 3090-3105.

Sun, F., Hall, A., Schwartz, M., Walton, D., \& Berg, N. (2016). 21st-century snowfall and snowpack changes in the Southern California mountains. Journal of Climate, 29(1), 91-110. https://doi.org/10. 1175/JCLI-D-15-0199.1.

Van Fraassen, B. C. (1980). The scientific image. Oxford: Clarendon Press.

Van Fraassen, B. C. (2004). Science as representation: Flouting the criteria. Philosophy of Science, 71, 794-804.

Van Fraassen, B. C. (2008). Scientific representation: Paradoxes of perspective. Oxford: Oxford University Press.

Walton, D. B., Hall, A., Berg, N., Schwartz, M., \& Sun, F. (2016). Incorporating snow albedo feedback into downscaled temperature and snow cover projections for California's Sierra Nevada. Journal of Climate. https://doi.org/10.1175/JCLI-D-16-0168.1. (in press).

Wang, C., Jones, R., Perry, M., Johnson, C., \& Clark, P. (2013). Using an ultrahigh-resolution regional climate model to predict local climatology. Quarterly Journal of the Royal Meteorological Society, 139, 1964-1976. https://doi.org/10.1002/qj.2081.

Weisberg, M. (2006). Robustness analysis. Philosophy of Science, 73(5), 730-742.

Westra, S., Fowler, H. J., Evans, P., Alexander, L. V., Berg, P., Johnson, F., et al. (2014). Future changes to the intensity and frequency of short-duration extreme rainfall: Future intensity of sub-daily rainfall. Reviews of Geophysics. https://doi.org/10.1002/2014rg000464.

Publisher's Note Springer Nature remains neutral with regard to jurisdictional claims in published maps and institutional affiliations. 